\title{
Being popular or freak: how alien plants integrate into native plant-frugivore networks
}

\author{
Tobias Nicolas Rojas (D) María Cecilia Fátima Gallo • David Lautaro Vergara-Tabares • \\ María Gabriela Nazaro • Iris Catiana Zampini • María Inés Isla • \\ Pedro G. Blendinger (i)
}

Received: 30 May 2018/ Accepted: 27 April 2019

(C) Springer Nature Switzerland AG 2019

\begin{abstract}
The generalist diet of most frugivores opens a window of opportunity to the invasion of alien plants whit fleshy-fruits. The outcome of the new relationships between alien plants and native frugivores depends both on traits of the invaders and of the mutualist partners in the recipient community. Two contrasting hypotheses attempt to explain the integration of alien species in native communities. "Darwin's naturalization hypothesis" proposes that alien species more different from native species are more likely to
\end{abstract}

Electronic supplementary material The online version of this article (https://doi.org/10.1007/s10530-019-01997-9) contains supplementary material, which is available to authorized users.

T. N. Rojas $(\bowtie) \cdot$ M. G. Nazaro · P. G. Blendinger Instituto de Ecología Regional, Universidad Nacional de Tucumán \& CONICET, CC 34, 4107 Yerba Buena, Tucumán, Argentina

e-mail: tobiasnrojas@gmail.com

M. C. F. Gallo

Instituto de Biotecnología Farmacéutica Y Alimentaria, Universidad Nacional de Tucumán \& CONICET, Av.

Kirchner 1900, 4000 San Miguel de Tucumán , Tucumán, Argentina

D. L. Vergara-Tabares

Instituto de Diversidad Y Ecología Animal, Universidad Nacional de Córdoba \& CONICET, Vélez Sarsfield 299, 5000 Córdoba, Argentina integrate in the community. The "similarity hypothesis" proposes the opposite, that alien species more similar to native species are more likely to integrate the native community. By comparing chemical and morphological traits of 12 alien and 48 native fleshyfruited species, we tested both hypothesis as assembly rules of alien species in subtropical Andean forests. We did not find differences in most chemical or morphological traits between alien and native fruit species. The multidimensional variation of alien fruit traits was nested within that of native species. However, alien fruits tended to score high in the range of variation of native chemical traits. Accordingly, we propose the "fraction similarity hypothesis" as a main

\section{C. Zampini · M. I. Isla \\ Instituto de Bioprospección Y Fisiología Vegetal, Universidad Nacional de Tucumán \& CONICET, San Lorenzo 1469, 4000 San Miguel de Tucumán, Tucumán, Argentina \\ I. C. Zampini · M. I. Isla · P. G. Blendinger \\ Facultad de Ciencias Naturales e Instituto Miguel Lillo, \\ Universidad Nacional de Tucumán, Miguel Lillo 2005, \\ 4000 San Miguel de Tucumán, Tucumán, Argentina}


force that drive the assembly of alien species in mutualistic networks, i.e. alien species benefit from existing mutualistic interactions that involve fruit species with traits selected by the frugivores to invade native communities. The striking similarity in fruit traits between alien and native species highlights the potential role of seed dispersers as ecological filters to the invasion of alien plants. In turn, this similarity suggests that alien fruits can be functionally equivalent to native ones in terms of their interaction with fruit-eating birds.

Keywords Fruit traits - Invasive species · Darwin's naturalization hypothesis - Similarity hypothesis .

Seed dispersal mutualism · Subtropical Andean forests

\section{Introduction}

In the last centuries, human activity favoured the introduction of thousands of fleshy-fruited species into new ecosystems, where some of them (ca. 600 species only for trees and shrubs; Richardson and Rejmánek 2011) became invasive by interacting with the native biota and having the ability to grow and reproduce in the novel environments (Pantel et al. 2017). Interactions between fleshy-fruited plants and seed-disperser animals often result in the removal of plant diaspores ("fruits") as foraging animals reach part of their dietary requirements (Howe and Smallwood 1982). The outcome of these new relationships between alien plant species and native fruit-eating animals depends both on attributes of the invader and of the mutualist partners in the recipient community (Kueffer et al. 2009). Bearing fleshy-fruits dispersed by birds -the globally most diverse group of dispersers- might explain the invasiveness of many alien species around the world, especially of those with large crop sizes (Buckley et al. 2006; Giorgis et al. 2010; Gleditsch and Carlo 2011; Cronk and Fuller 2014). Thus, morphological and phytochemical traits seem to be important cues for fruit-eating birds (Blendinger et al. 2015). Moreover, although fruit traits could drive to the consumption of alien species, the role of these traits on the integration of alien species in native communities is poorly understood (Kueffer et al. 2009; Minoarivelo and Hui 2016; Hulme and Bernard-Verdier 2018).
Fruits show a variable combination of traits that allow them to interact with frugivores and promote seed dispersal, including morphological (colour, shape and size) and chemical (nutrients, water content, secondary compounds) traits (Schaefer and Ruxton 2011). Not all traits are of equal weight regarding foraging decisions by consumers, and the relative importance of a particular fruit trait or trait combination for seed dispersal could depend on idiosyncrasies of the frugivores (Blendinger et al. 2016; Bender et al. 2017). Bird selection of alien fruits seems to be influenced by the interaction between enhanced foraging efficiency and shared traits of alien with native fruits (Aslan and Rejmánek 2012). On the one hand, alien plant species with relatively higher crop size than native plants are presumed to attract more fruit-eating birds, which concentrate their foraging activity where resources are most abundant (Gleditsch and Carlo 2011; Mokotjomela et al. 2013a). On the other hand, the selection of fruits of alien species may be related to fruit traits, such as greater size and higher pulp-to-seed ratio, sugar concentration, and energy rewards (Kueffer et al. 2009; Mokotjomela et al. 2013b). Moreover, fruit traits found in a particular species may have been shaped through the interaction with the regional pool of seed dispersers (Schaefer et al. 2007; Valido et al. 2011; Guimarães et al. 2017), other fleshy-fruited plants (Schaefer et al. 2004; Stournaras and Prum 2015), and seed and fruit predators (Buchholz and Levey 1990; Cipollini and Levey 1997; Cipollini 2000). Altogether, these processes may have left an imprint in fruit traits through the evolutionary history of plant lineages. Consequently, fruit traits that have evolved in different dispersion contexts could be expected to vary among geographic regions.

Thus far, two main contrasting hypotheses aim to explain the integration of alien species into native communities. On the one hand, the 'Darwin's naturalization hypothesis' (DNH) states that a given alien species can better settle in novel environments when being more different from the native species in one or more traits (Traveset and Richardson 2011). The DNH assumes that it is easier to integrate to a given community when the putative competition is avoided by exhibiting different traits, either categorical or in terms of magnitude, compared to those of native species (Phillimore et al. 2008; Thuiller et al. 2010). On the other hand, assuming that the diversity of traits in native assemblages is moulded by the mutualistic 
interactions in native communities (Guimarães et al. 2017; Pantel et al. 2017), the similarity of alien species with the existent native traits could promote the invasion (Traveset and Richardson 2011), as the hereafter referred to as the 'similarity hypothesis' (SH) argues. Specifically, SH proposes that in plant seed-disperser interactions, traits that define the interaction between novel flora and native seed-dispersers are determined by the interaction of native flora with native seed-dispersers. In consequence, the more similar the alien species traits to the receiver community, the more likely its integration to that community (Traveset and Richardson 2011). A third possible explanation is that alien plants share trait values with the native fleshy fruits more selected by frugivores. This explanation is partially similar to the $\mathrm{SH}$ mechanism, but it differs in that aliens are similar to a particular fraction of the native flora, rather than to the whole receiver community. We referred to this explanation as the 'fraction similarity hypothesis' (FSH). This idea is an expansion of the 'limiting similarity hypothesis' (LSH) proposed by MacArthur and Levins (1967). These authors conclude that limitations in trait variation are due to competition. Then, invasions are promoted under certain conditions in which trait values are not overlapped between species or when the overlap do not generate competitive exclusion (i.e. stable competition; MacArthur and Levins 1967). Thus, according to LSH, alien species are constrained to invade by niche partitioning assuming avoidance of competition (or a stable competition). A fundamental difference between FSH and LSH is that MacArthur and Levins (1967) assume competition between species. In the other hand, FSH stated that alien species benefit from existing mutualistic interactions that involve fruit species with traits selected by the frugivores to invade native communities.

Recently, $\mathrm{Ng}$ et al. (2019) highlights the need to consider data from phenotypic traits to test these hypotheses as predictive tools for community invasion. To date, explanations regarding how alien species overcome biotic filters imposed by native seed dispersers, and how they integrate into recipient communities are still scarce (Gurvich et al. 2005; Hulme and Bernard-Verdier 2018). In particular, whether a trait or combination of traits are responsible of such integration, and whether this is facilitated by similarities or differences with native species remains unknown (Traveset and Richardson 2011, 2014; Aslan and Rejmánek 2012). In this study, we assess whether alien plants display novel values of fruit traits that are important for the interaction with seed dispersers (DNH); or if, instead, trait values shared with native flora $(\mathrm{SH})$; or with a fraction of the native plant assemblage (FSH) prevail. To understand the ecological forces that might drive the integration of alien species in native plant-frugivore networks; we compare morphological and chemical fruit traits of 60 species of alien and native plants dispersed by birds in subtropical Andean forests.

\section{Methods}

We conducted the study in subtropical Andean cloud forests known as Austral Yungas. In these forests, the native plant-frugivore mutualistic network includes at least 58 species of seed dispersers, belonging to 13 bird families and 7 mammal families, who feed regularly on fleshy-fruits of around 240 plant species of 61 families (Blendinger et al. 2015; Ruggera et al. 2016, PG Blendinger and NP Giannini unpubl.). We performed the field work in nine localities of Tucumán province $\left(26^{\circ} 23^{\prime}-27^{\circ} 40^{\prime} \mathrm{S}, 64^{\circ} 55^{\prime}-65^{\circ} 57^{\prime} \mathrm{W}\right)$, northwest Argentina, over the entire range of vegetation elevation belts (ca. 500-1900 m a.s.l., Brown et al. 2001). Climate is subtropical, with dry winters (May to September) and wet summers (November to March). Average annual rainfall varies between 1100 and $1500 \mathrm{~mm}$ throughout the mountain range, with ca. $80 \%$ of rainfall occurring in summer. Average annual temperature is $19{ }^{\circ} \mathrm{C}$ (Hunzinger 1997). In the recent decades, at least 15 fleshy-fruited alien species became invasive in the area (Aragón and Morales 2003; Sirombra and Mesa 2012). These plants interact with native frugivores, which eventually disperse their seeds (Aragón 2000; Blendinger and Giannini 2010; Powell and Aráoz 2017). Most alien and native fruit species bear typical ornitochorous fruits, and it is known that birds eat them and disperse their seeds (Richardson and Rejmánek 2011; Ruggera et al. 2016; Ordano et al. 2017).

From 2013 to 2017, we collected fresh fruits of native and alien bird-dispersed plants throughout the year, for posterior chemical analyses. We collected fruits randomly from different plants of each species. We selected only ripe fruits without blemishes or 
damage, we cleaned each fruit with distilled water, and freeze-dried them. Once freeze-dried, we removed the seeds from the pulp with forceps and needles. We stored freeze-dried seedless pulp samples at $-20{ }^{\circ} \mathrm{C}$ until analysed. We were able to complete the dataset of chemical and morphological traits of 48 native and 12 alien plant species (Online resource1, Table S1). These species include the different growth forms (forbs, epiphytes, shrubs, vines and trees) which bear fleshy fruits dispersed by birds in the study area.

\section{Morphological traits}

We considered a fleshy fruit according to its ecological role in mutualistic interactions, i.e. as the reproductive unit consumed by fruit-eating birds. We collected a minimum of 10 to 30 ripe fruits of the larger species (i.e. $>5 \mathrm{~g}$ per fruit) and until reach 100 to $300 \mathrm{~g}$ for small fruits ( $<5 \mathrm{~g}$ per fruits), from different plants of each species. Variations in the amount collected depended on fruit availability and fruit mass inside both categories. We measured maximum fruit length and width with a digital calliper to the nearest $0.1 \mathrm{~mm}$. We weighted the mass of the whole fresh fruit with a digital scale to the nearest $0.1 \mathrm{mg}$, and the mass of individual seeds with a precision lab scale to the nearest $0.01 \mathrm{mg}$. We then counted the number of seeds per fruit. With the raw data, we estimated the mean values of these, plus the mean value of fruit shape (fruit length/fruit width), total seed mass per fruit, and pulp-to-seed ratio (fruit mass/total seed mass).

\section{Chemical composition}

We carried out sugar, and total phenolic determinations with ethanolic extracts (EE). Also, we extracted proteins with an aqueous extraction (AE). To prepare EE we first extracted fruit powder with $96^{\circ}$ ethanol (0.071 g dry pulp/ $\mathrm{ml}$ of ethanol) for $24 \mathrm{~h}$. Then, we filtered the extract with Whatman $\mathrm{N}^{\circ} 4$ filter paper and we used the supernatant for chemical analysis. We performed the same procedure for $\mathrm{AE}$, using distilled water instead of ethanol.

\section{Sugar determination}

We determined total sugars on EE by the phenolsulphuric acid method (DuBois et al. 1956). We took aliquots $(0.8 \mathrm{ml})$ of different extract dilutions, and measured the absorbance in an UV-visible BeckmanDU-650 spectrophotometer (490 nm). We performed a calibration curve using glucose as a standard and expressed the results as milligrams of glucose equivalents per gram of dry pulp mass (mg GE/g).

\section{Protein determination}

We quantified total soluble proteins according to Bradford (1976) using bovine serum albumin as standard. We took aliquots $(0.1 \mathrm{ml})$ of different EE extract dilutions and added $5 \mathrm{ml}$ of dye solution (Coomassie Brilliant Blue G 250). We measured absorbance at $595 \mathrm{~nm}$ and performed a calibration curve with bovine serum albumin, expressing the results as milligrams of bovine serum albumin equivalents per gram of dry pulp mass (mg BSAE/g).

\section{Lipids}

We extracted lipids with a Soxhlet extractor. We put $1 \mathrm{~g}$ of dried pulp in a cellulose cartridge, and then placed the cartridge in the extractor with $150 \mathrm{ml}$ of petroleum ether $60-80^{\circ} \mathrm{C}$, extracting lipids until exhaustion. We then evaporated the petroleum ether and weighted the extract using an analytic scale, assuming it is the lipid content. We expressed lipid content as milligrams of lipids per gram of dry pulp $(\mathrm{mg} / \mathrm{g})$.

\section{Mineral content}

Once weighed $(0.20 \mathrm{~g})$, we mixed the lyophilized samples with sub-boiling HNO3 $(8 \mathrm{~mL})$ in a quartz glass and maintained it for $45 \mathrm{~min}$ in a microwave oven at $280{ }^{\circ} \mathrm{C}$ and 75 bars. We then added Milli Q water until it reached a volume of $25 \mathrm{~mL}$ and filtered the disintegrated material through a $0.45-1 \mathrm{~m}$ filter. We determined the levels of $\mathrm{Na}, \mathrm{K}, \mathrm{Ca}, \mathrm{Fe}$ and $\mathrm{Mg}$ of these solutions by inductively coupled plasma mass spectrometry (ICP-MS). We expressed the results as milligrams per $100 \mathrm{~g}$ of dry pulp mass (mg mineral/ $100 \mathrm{~g})$.

\section{Water content}

We determined water content by subtracting the dried fruit-pulp weight by fresh fruit-pulp weight. Then, we 
transformed the weight value into a ratio, for better comparison between species.

\section{Total phenolics}

Total phenolics were determined on EE extract using Folin- Ciocalteu's reagent, following the description in Singleton et al. (1999), with certain modifications mentioned below. The reaction mixture contained different quantities of each EE, $100 \mu \mathrm{l}$ of FolinCiocalteu's reagent and $400 \mu \mathrm{L}$ of sodium carbonate $(15.9 \% \mathrm{w} / \mathrm{v})$ and reached to $1500 \mu \mathrm{L}$ with distilled water. Total phenolic content was determined by the comparison with a calibration curve of gallic acid as a standard. We measured absorbance at $765 \mathrm{~nm}$ and expressed results as milligrams of gallic acid equivalents per gram of dry pulp mass (mg GAE/g).

\section{Tannins}

We extract tannins using an acetone-distilled water 1:1 solution. We put $0.1 \mathrm{~g}$ of dried fruit pulp into an eppendorf tube, and then added $1.2 \mathrm{ml}$ of extraction solution. We centrifuged at $10,000 \mathrm{rpm}$ and filtered the extraction. We repeated the process until exhaustion, and subsequently dried the extractions. Then, we measured condensed tannins using $1 \%$ dimethilamino-cinnamaldehide (DMAC) as reactive. We resuspended the samples with $1.5 \mathrm{ml}$ of distilled water; and added $0.2 \mathrm{ml}$ of the sample into an assay tube with $0.9 \mathrm{ml}$ of DMAC. We left the solution at room temperature for $20 \mathrm{~min}$ and read absorbance at $640 \mathrm{~nm}$. We expressed results as grams of procianidine-B2 equivalents/dry fruit grams (g PB2E/g).

\section{Statistical analysis}

With the raw data we estimated the mean of each trait. We first independently compared the 19 fruit traits between groups (alien vs. Native) using GLMMs, with taxonomic order as random effect. We fitted a Gaussian distribution for all the comparisons, except for water content (beta distribution) and seed number (negative binomial distribution). Next, to avoid the usage of collinear variables, we performed a Pearson correlation analysis and dismissed one of two correlated variables whenever the Pearson correlation coefficient was larger than 0.7 (Online resource1, Fig.S1). Finally, we used the non-collinear variables to analyse the multivariate space filled by alien and native bird-dispersed fleshy fruits. Since not all the trait data were available for all the species in order to perform the ordination analysis (Online resource 1, Table S1), we performed a paired comparison between species vectors containing trait values of each species i.e. one vector by species- using Gower distances to estimate the dissimilarity.

The result of each vector comparison was used to build a dissimilarity matrix used to run a non-metric multidimensional scaling with 9999 permutations (NMDS; see methods in Giannini and García-López 2014). In this way, we avoided discarding entire species due to lacking of few measurements. We selected the number of axis as a compromise between stress, interpretation difficulty, and clarity in the detection of patterns. We then ran an analysis of similarities (ANOSIM) to test whether alien and native species could be grouped into discrete groups of species in the ordination space. Also, we performed a test (PERMDISP) to corroborate that the assumption of "multivariate homogeneity of group dispersions" of the ANOSIM be fulfilled (Oksanen et al. 2017). Finally, we fitted trait values to the NMDS to elucidate which traits were more important for the ordination (Oksanen et al. 2017). We used lme4 package (Bates et al. 2015) to perform the GLMMs; basic commands of R (R Development Core Team 2016) to construct the matrix, and the vegan package for the dissimilarity distance calculation, NMDS, ANOSIM and PERMDISP analyses (Oksanen et al. 2017).

\section{Results}

Of the 19 fruit traits analysed, $\mathrm{K}$ and $\mathrm{Fe}$ differed between alien and native fruit groups (GLMM, $p<0.05$; Table 1). The remaining traits did not differ between both groups of fruit species. Coefficients of variation were smaller in aliens than in natives for most fruit traits, except for sugars and tannins that showed similar values and pulp-to-seed ratio that was larger in aliens (Table 1).

After Pearson correlation analysis, we kept 15 noncollinear variables (Online resource1, Fig. S1) for the ordination analysis. Stress value of the NMDS was 0.18 for 3 dimensions. NMDS did not show a clear differentiation pattern between groups of native or alien plants (Fig. 1a, b). There was no difference 
Table 1 Comparison of fruit traits between alien and native fleshy-fruited bird-dispersed species

\begin{tabular}{|c|c|c|c|c|c|}
\hline Trait & Alien (CV) & Native (CV) & $d f$ & $t$ & $p$ \\
\hline Length & $15.42 \pm 9.17(0.59)$ & $13.97 \pm 18.04(1.29)$ & 57.00 & -1.002 & 0.321 \\
\hline Width & $11.63 \pm 6.50(0.56)$ & $10.12 \pm 6.69(0.66)$ & 53.32 & -0.834 & 0.408 \\
\hline Shape & $1.33 \pm 0.43(0.32)$ & $1.56 \pm 2.54(1.63)$ & 56.33 & -0.793 & 0.431 \\
\hline Total mass & $1.99 \pm 3.04(1.50)$ & $1.46 \pm 4.34(2.96)$ & 40.77 & -0.612 & 0.544 \\
\hline All seeds mass & $0.39 \pm 0.71(1.83)$ & $0.32 \pm 0.91(2.81)$ & 48.44 & -0.717 & 0.477 \\
\hline One seed mass & $0.34 \pm 0.67(2.02)$ & $0.11 \pm 0.36(3.24)$ & 56.98 & -1.083 & 0.283 \\
\hline Seed number & $17.20 \pm 29.79(1.73)$ & $63.02 \pm 132.97(2.11)$ & 53.00 & 1.550 & 0.121 \\
\hline Pulp-to-seed ratio & $11.19 \pm 17.52(1.57)$ & $10.29 \pm 11.68$ & 56.00 & 0.635 & 0.528 \\
\hline Sugars & $211.05 \pm 138.76(0.66)$ & $143.39 \pm 94.36(0.66)$ & 52.86 & -1.827 & 0.073 \\
\hline Lipids & $0.039 \pm 0.052$ & $0.038 \pm 0.088(2.32)$ & 24.11 & -1.171 & 0.253 \\
\hline Proteins & $1.16 \pm 0.51(0.45)$ & $0.52 \pm 0.79(1.51)$ & 33.65 & -2.033 & 0.050 \\
\hline Water & $77.52 \pm 7.17(0.09)$ & $78.80 \pm 11.87(0.15)$ & 32.14 & 0.667 & 0.509 \\
\hline Phenolics & $2008.18 \pm 1278.55(0.64)$ & $2841.96 \pm 3226.86(1.14)$ & 54.37 & 0.934 & 0.355 \\
\hline Tannins & $608.18 \pm 1114.22$ & $1101.21 \pm 2024.42$ & 49.73 & 1.466 & 0.149 \\
\hline $\mathrm{Ca}$ & $592.81 \pm 358(0.60)$ & $345.56 \pm 302.15(0.87)$ & 30.03 & -1.798 & 0.082 \\
\hline $\mathrm{Fe}$ & $6.65 \pm 4.39(0.66)$ & $4.40 \pm 25.06(1.61)$ & 53.00 & 2.008 & 0.049 \\
\hline $\mathrm{Mg}$ & $122.85 \pm 86.96(0.71)$ & $169 \pm .42 \pm 164.95(0.97)$ & 32.64 & 1.142 & 0.262 \\
\hline $\mathrm{K}$ & $1418.46 \pm 436.24(0.31)$ & $2536.33 \pm 1412.65(0.56)$ & 52.49 & 2.015 & 0.049 \\
\hline $\mathrm{Na}$ & $9.84 \pm 5.29(0.54)$ & $20.54 \pm 25.51(1.24)$ & 53.00 & 0.656 & 0.514 \\
\hline
\end{tabular}

Alien and native columns indicate the mean \pm standard deviation (coefficient of variation) of each group. Sugars, proteins and phenolics are expressed in equivalents of standard per dry pulp (mg GE/g, mg BSA/g, and mg GAE/g, respectively); minerals (Ca, $\mathrm{Fe}, \mathrm{K}, \mathrm{Mg}, \mathrm{Na}$ ) in mg/100 g of dry pulp; fruit mass in $\mathrm{mg}$; water in \%; pulp-to-seed ratio and fruit shape are non-dimensional. The last three columns report results of GLMM; between traits differences in degrees of freedom $(d f)$ are because of differences in sample size and in representation in different taxonomic groups when we compute the random effects (see "Methods" section for details)

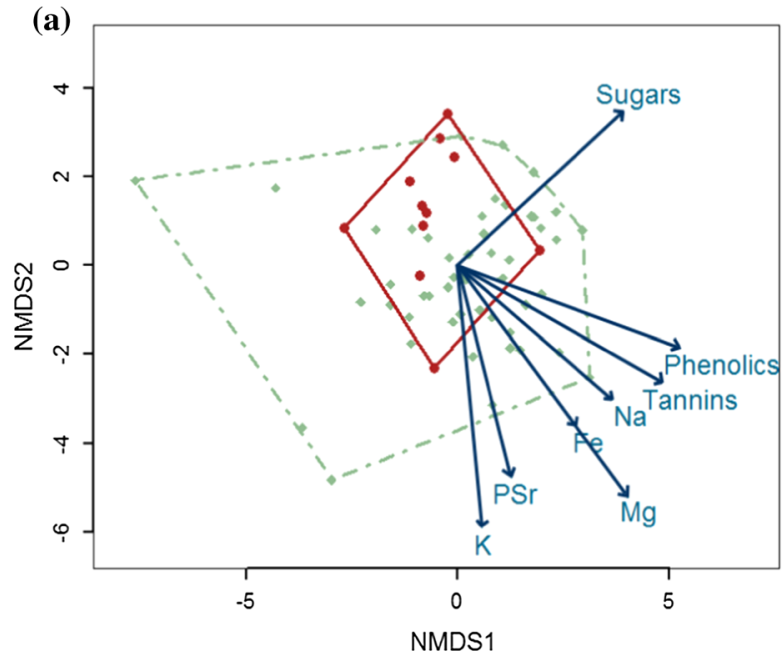

Fig. 1 NMDS plots of axis 1 and 2 (a); and axis 2 and 3 (b). Alien species in circles and native species in diamonds. Green and red lines connect species to the centroid of native and alien fruits respectively. Polygons contour the multivariate space

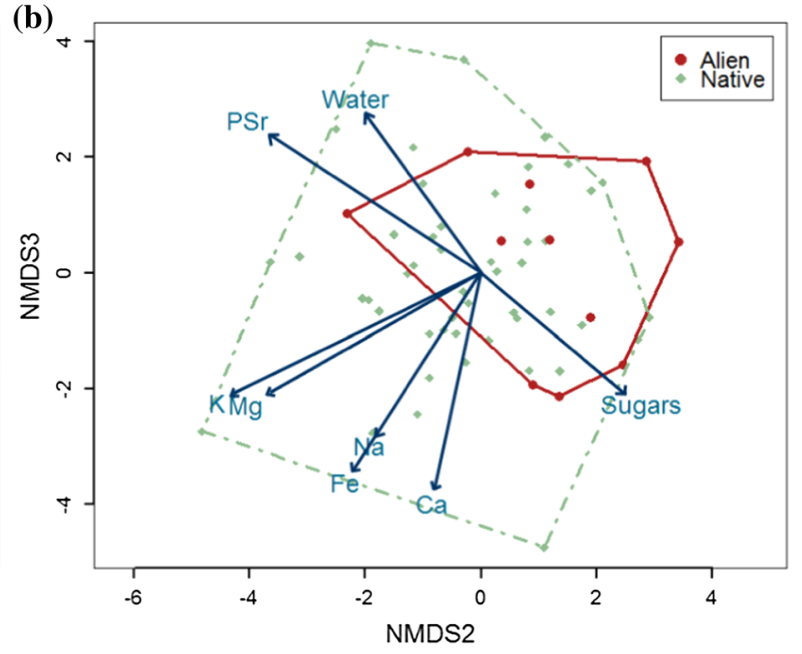

occupied by each group (natives: dot-dashed green line, aliens: continuous red line). Blue vectors are the fruit trait variables that better fit the ordination $(p$ value $<0.05$ ) 
between alien and native fruits in the ordination space $($ ANOSIM test; $\mathrm{R}$ statistic $=0.068, p$ value $=0.253$ ). The multivariate dispersion of alien and native fruits did not differ from homogeneity (PERMDISP; $p$ value $=0.457)$.

Important variables that structured the NMDS ordination were pulp-to-seed ratio (PSr in Fig. 1), water, phenolics, tannins, sugars, $\mathrm{Ca}, \mathrm{K}, \mathrm{Na}, \mathrm{Fe}$ and $\mathrm{Mg}$ (Fig. 1). As showed by polygons in Figs. 1a, b, alien plants (continuous line) are ordered inside native variation (dot-dashed line). Minerals structured the ordination as a whole, i.e. all mineral vectors increased in the same direction in the ordination planes. Besides, the centroid of alien plants was related to lower concentrations of minerals and phenolics (Fig. 1a, b). Figure S2 (Online resource1) condenses the information of the previous analysis and shows the dispersion of values in each statistically significant trait important for the NMDS. We included proteins and sugars and lipids, because these three macronutrients are proposed as important traits for bird decisions (Aslan and Rejmánek 2012; Blendinger et al. 2015). K and Fe differed between fruit groups and were important for the ordination. As noted also by coefficients of variation (Table 1), most fruit traits showed less variation in alien than native fruits.

\section{Discussion}

The comparison of fruit traits, both as a whole and separately, can provide insights about important traits that influence the invasion of fleshy-fruited plants (Gosper and Vivian-Smith 2010; Aslan and Rejmánek 2012). Our community-wide analysis highlight that native and alien plants dispersed by birds share many fruit traits, strongly suggesting that species assembly rules proposed by the similarity hypothesis (as opposed to Darwin's naturalization hypothesis) are the norm in subtropical Andean forests. Despite the similarity between groups of fruits of different geographical provenances, alien species differ from native species in certain particular chemical fruit traits $(\mathrm{K}$ and $\mathrm{Fe}$ content). This leads us to think that another mechanism different from the prevailing hypotheses could also be promoting the integration of alien species. It is likely that fruit-eating birds selectively promote the dispersal of alien species that display high values of native flora fruit traits selected by birds.
In line with other studies in subtropical climates (e.g. Gosper and Vivian-Smith 2010; Jordaan and Downs 2012), we did not find a clear differentiation between alien and native plant species in the multivariate space in terms of fleshy-fruit traits of morphological design or nutritional content. The diffuse nature of plant-seed disperser interaction positions the whole range of dispersers as selective agents (Guimarães et al. 2017). Thus, seed-dispersers assemblages could act as biotic filters for the settlement of novel species in native systems (Pantel et al. 2017). If plant species share functional partners in their natural range, and share a similar evolutionary history, it is expected for them to share traits that allow them to interact with similar mutualist partners in different environments (Pantel et al. 2017). Thus, fruit-eating birds affect plants with their selection idiosyncrasies, and by filtering them through their consumption of fruits (Blendinger et al. 2016; Pantel et al. 2017). This putative fruit trait convergence is a possible underlying SH and FSH mechanism. However, SH involves the similarity of the means of the traits (or the centroid of multiple traits), while FSH involves the similarity of a fraction of the total variability. In our study, alien species were less variable in most traits. They occupied a short range of variation nested within a portion of native plants variation. Trait-by-trait comparisons also showed the same pattern. The description of this pattern could be due to an unbalanced comparison -12 alien versus 48 native species- but considering the low taxonomical relationships between species and the differences found for some variables in the trait-by-trait comparison, we believe that is not a major issue when interpreting the results.

Certain chemical traits differed between native and alien fruit species in our study site, while morphological traits did not. Previous assessments of particular fruit traits at the community level showed some differences in the morphological traits (e.g. seed number) of native and alien species, and mostly in their chemistry (e.g. sugar and nitrogen levels, water and energy content), although with trends of variable sign among studies (Kueffer et al. 2009; Gosper and Vivian-Smith 2010; Jordaan and Downs 2012; Mokotjomela et al. 2013a, b). To understand the ecological importance of native and alien fruit traits, the variation of fruit traits at the community level should be compared in addittion to the differences (Traveset and Richardson 2011; Hulme and Bernard- 
Verdier 2018). Kueffer et al. (2009) were possibly the first to compare fruit trait variation at a regional scale, using a set of native and alien species of tropical oceanic islands. They found higher variation in alien than in native species, and native species in general scored lower in all traits they studied except water content. In contrast, alien fruit traits were narrower compared to those of native fruits in subtropical Andean forests, only sugars and tannins showing almost the same variation in alien and native species and pulp-to-seed ratio shows higher variation in aliens (Table 1). The apparent lack of consistency between these studies could be reflecting different mechanisms that play a relevant role in the invasion/colonization process. In less diverse communities, like oceanic islands, where frugivorous populations are more likely to be limited by resources, plants capable of adding more quantities of certain nutrients seems to be more likely to be selected by dispersers, and thus, to become invasive. On the other hand, in more diverse communities where the functional niche of fleshy fruits is widely occupied, alien species exploit the ecological space occupied by traits already chosen by seed dispersers (Pantel et al. 2017). In a receptive community, more potential mutualists occur when the functional and taxonomical diversity increase (Hui et al. 2016; Minoarivelo and Hui 2016). Thus, alien fruits that are functional equivalent with native fruits are more likely to integrate into native communities, leading to narrowing their ecological niche rather than to an expansion of the functional space in the community (e.g. Pigot et al. 2016). However, it is also likely that the wider range of traits displayed by native fruits in diverse communities hinder the occurrence of novelties originated in other communities with different evolutionary histories. Thus, a interesting challenge is to decouple if similarity of alien plants with native flora are due to the impossibility of being different because occurrence of all variation spectrum of traits or if similarity per se promotes invasion.

Interestingly, fruits of alien species tended to score in the upper range of variation of particular chemical traits of the native species in subtropical Andean forests. One possible explanation is that fruit-eating birds select alien species that display high values of the fruit traits selected in the native fruits. This has not been tested to date and may explain the apparent idiosyncrasy of responses across studies mentioned above. In subtropical Andes, fruit-eating birds have strong preferences in the consumption of native fruit species (TN Rojas, in prep.), and select native fruit species that score high in pulp and chemical rewards (Blendinger et al. 2016). Whether alien species have similar nutritionally relevant fruit traits of the preferred native fruit species, or offer greater quantities of rewards that are low in native species, alien species could integrate into the communities through the complementarity of diet and fruit mixing behaviour of dispersers (Felton et al. 2009; Carlo and Morales 2016).

In summary, fruit traits are important in the invasion process, because they allow plants to interact with seed dispersers of the native communities (Schaefer et al. 2003; Gosper and Vivian-Smith 2010; Aslan and Rejmánek 2012). In diverse communities, alien plants are able to integrate to extant seed dispersal networks through similar trait combinations with native plants. We showed that the variability in alien fruit-traits is nested in the multivariate space of native fruits, suggesting that alien fruits are functionally equivalent to those found in the native community. This niche overlap suggests that invasive alien plants could exploit the already extant mutualisms and thus, settle in the native community. In this way, not all alien fruit species integrate a native community, but aliens are filtered by the preference and idiosyncrasies of seed-dispersers. In other words, alien plants overcome filters imposed by seed-dispersers when they are capable of offering similar signals and rewards as natives do. Empirical and theoretical studies using networks as a framework show similar interpretations (Hui et al. 2016; Minoarivelo and Hui 2016; Pantel et al. 2017). This highlights the need of integrating the information here generated with interaction information (e.g. consumption, networks) to get the full picture. Taking into account the evidence provided, we suggest not to discard the "fraction similarity hypothesis" as an important mechanism that favours the invasion of alien species in Andean forests. However, to test this hypothesis it is mandatory to further explore the influence of seed dispersers as ecological filters. We encourage the realization of studies that take consumption into account, to disentangle the effect of similarities and differences between alien and native fleshy-fruited plants in the invasion process. 
Acknowledgements We are very grateful with Agustín Quaglia, Lucía Zarbá, Norberto Giannini and Sebastian Zeballos for helpful advises on methodology and Romina Chavez for valuable contribution in figures editing. We acknowledge funding by Consejo Nacional de Investigaciones Científicas y Técnicas (CONICET; PIP 2014-592) and Fondo para la Investigación Científica y Tecnológica (FONCyT; PICT 2013-1280).

\section{References}

Aragón R (2000) Especies exóticas como recurso para las aves. In: Grau RH, Aragón R (eds) Árboles Exóticos de las Yungas Argentinas. LIEY UNT, Denton, pp 21-35

Aragón R, Morales JM (2003) Species composition and invasion in NW Argentinian secondary forests: Effects of land use history, environment and landscape. J Veg Sci 14:195-204. https://doi.org/10.1111/j.1654-1103.2003. tb02144.x

Aslan C, Rejmánek M (2012) Native fruit traits may mediate dispersal competition between native and non-native plants. NeoBiota 12:1-24. https://doi.org/10.3897/ neobiota.12.2357

Bates D, Maechler M, Bolker B, Walker S (2015) Fitting linear mixed-effects models using lme4. J Stat Softw 67:1-48. https://doi.org/10.18637/jss.v067.i01

Bender IMA, Kissling WD, Katrin B et al (2017) Functionally specialised birds respond flexibly to seasonal changes in fruit availability. J Anim Ecol 84:800-811. https://doi.org/ 10.1111/1365-2656.12683

Blendinger PG, Giannini NP (2010) Interacciones planta-animal en la sierra de San Javier. In: Grau RH (ed) Ecología de una interfase natural - urbana. La sierra de San Javier y el Gran San Miguel de Tucumán, EDUNT, Tucumán, pp 93-117

Blendinger PG, Giannini NP, Zampini IC et al (2015) Nutrients in fruits as determinants of resource tracking by birds. Ibis 157:480-495. https://doi.org/10.1111/ibi.12274

Blendinger PG, Martín E, Osinaga-Acosta O et al (2016) Fruit selection by Andean forest birds: influence of fruit functional traits and their temporal variation. Biotropica 48:677-686. https://doi.org/10.1111/btp.12329

Bradford MM (1976) A rapid and sensitive method for the quantitation of microgram quantities of protein utilizing the principle of protein-dye binding. Anal Biochem 72:248-254. 2697(76)90527-3

Brown AD, Grau HR, Malizia LR, Grau A (2001) Bosques Nublados del Neotrópico. IMBIO, San José

Buchholz R, Levey D (1990) The evolutionary triad of microbes, fruits, and seed dispersers: an experiment in fruit choice by cedar waxwings, Bombycilla cedrorum. Oikos 59:200-204

Buckley YM, Anderson S, Catterall CP et al (2006) Management of plant invasions mediated by frugivore interactions. J Appl Ecol 43:848-857. https://doi.org/10.1111/j.13652664.2006.01210.x

Carlo TA, Morales JM (2016) Generalist birds promote tropical forest regeneration and increase plant diversity via rare- biased seed dispersal. Ecology 97:1819-1831. https://doi. org/10.1515/aiht-2015-66-25

Cipollini ML (2000) Secondary metaboltes of vertebrate-dispersed fruits: evidence for adaptive functions. Rev Chil Hist Nat 73:421-440

Cipollini ML, Levey DJ (1997) Secondary metabolites of fleshy vertebrate-dispersed fruits: adaptive hypotheses and implications for seed dispersal. Am Nat 150:346-372. https://doi.org/10.1086/286069

Cronk QCB, Fuller JL (2014) Plant invaders: the threat to natural ecosystems. Chapman \& Hall, Routledge

DuBois M, Gilles KA, Hamilton JK et al (1956) Colorimetric method for determination of sugars and related substances. Anal Chem 28:350-356. https://doi.org/10.1021/ ac60111a017

Felton AM, Felton A, Wood JT et al (2009) Nutritional ecology of Ateles chamek in lowland Bolivia: How macronutrient balancing influences food choices. Int J Primatol 30:675-696. https://doi.org/10.1007/s10764-009-9367-9

Giannini NP, García-López DA (2014) Ecomorphology of mammalian fossil lineages: identifying morphotypes in a case study of endemic South American ungulates. J Mamm Evol 21:195-212. https://doi.org/10.1007/s10914-0139233-6

Giorgis MA, Tecco PA, Cingolani AM et al (2010) Factors associated with woody alien species distribution in a newly invaded mountain system of central Argentina. Biol Invasions 13:1423-1434. https://doi.org/10.1007/s10530-0109900-y

Gleditsch JM, Carlo TA (2011) Fruit quantity of invasive shrubs predicts the abundance of common native avian frugivores in central Pennsylvania. Divers Distrib 17:244-253. https://doi.org/10.1111/j.1472-4642.2010.00733.x

Gosper CR, Vivian-Smith G (2010) Fruit traits of vertebratedispersed alien plants: smaller seeds and more pulp sugar than indigenous species. Biol Invasions 12:2153-2163. https://doi.org/10.1007/s10530-009-9617-y

Guimarães PR, Pires MM, Jordano P et al (2017) Indirect effects drive coevolution in mutualistic networks. Nature 550:511-514. https://doi.org/10.1038/nature24273

Gurvich DE, Tecco PA, Diaz S (2005) Plant invasions in undisturbed ecosystems: the triggering attribute approach. J Veg Sci 16:723-728. https://doi.org/10.1111/j.16541103.2005.tb02415.x

Howe HF, Smallwood J (1982) Ecology of seed dispersal. Annu Rev Ecol Evol Syst 13:201-228

Hui C, Richardson DM, Landi P et al (2016) Defining invasiveness and invasibility in ecological networks. Biol Invasions 18:971-983. https://doi.org/10.1007/s10530016-1076-7

Hulme PE, Bernard-Verdier M (2018) Comparing traits of native and alien plants: can we do better? Funct Ecol 38:117-125. https://doi.org/10.1111/1365-2435.12982

Hunzinger H (1997) Hydrology of montane forest in the Sierra de San Javier, Tucuman, Argentina. Mt Res Dev 17:299-308

Jordaan LA, Downs CT (2012) Nutritional and morphological traits of invasive and exotic fleshy-fruits in South Africa. Biotropica 44:738-743. https://doi.org/10.1111/j.17447429.2012.00875.x 
Kueffer C, Kronauer L, Edwards PJ (2009) Wider spectrum of fruit traits in invasive than native floras may increase the vulnerability of oceanic islands to plant invasions. Oikos 118:1327-1334. https://doi.org/10.1111/j.1600-0706. 2009.17185.x

MacArthur and Levins (1967) MacArthur R, Levins R (1967) The limiting similarity, convergence, and divergence of coexisting species. Am Nat 101:377-385

Minoarivelo HO, Hui C (2016) Invading a mutualistic network: to be or not to be similar. Ecol Evol 1-16. doi: 10.1002/ ece3.2263.

Mokotjomela et al (2013) TM Mokotjomela CF Musil KJ Esler 2013 Do frugivorous birds concentrate their foraging activities on those alien plants with the most abundant and nutritious fruits in the South African Mediterranean-climate region? Plant Ecol 214(49):59. https://doi.org/10. 1007/s11258-012-0145-y

Mokotjomela TM, Musil CF, Esler KJ (2013) Frugivorous birds visit fruits of emerging alien shrub species more frequently than those of native shrub species in the South African Mediterranean climate region. South African J Bot 86:73-78. https://doi.org/10.1016/j.sajb.2013.02.004

Ng J, Weaver WN, Laport RG (2019) Testing Darwin's Naturalization Conundrum using phylogenetic relationships: Generalizable patterns across disparate communities? Divers Distrib 25:361-373. https://doi.org/10.1111/ddi. 12861

Oksanen J, Blanchet FG, Friendly M, et al (2017) vegan: Community Ecology Package.

Ordano M, Blendinger PG, Lomáscolo SB et al (2017) The role of trait combination in the conspicuousness of fruit display among bird-dispersed plants. Funct Ecol 31:1718-1727. https://doi.org/10.1111/1365-2435.12899

Pantel JH, Bohan DA, Calcagno V et al (2017) 14 Questions for Invasion in Ecological Networks. Adv Ecol Res 56:293-340. https://doi.org/10.1016/bs.aecr.2016.10.008

Phillimore AB, Orme CDL, Thomas GH et al (2008) Sympatric speciation in birds is rare: insights from range data and simulations. Am Nat 171:646-657. https://doi.org/10. 1086/587074

Pigot AL, Trisos CH, Tobias JA (2016) Functional traits reveal the expansion and packing of ecological niche space underlying an elevational diversity gradient in passerine birds. Proc R Soc B 283:2013-2015. https://doi.org/10. 1098/rspb.2015.2013

Powell PA, Aráoz E (2017) Biological and environmental effects on fine- scale seed dispersal of an invasive tree in a secondary subtropical forest. Biol Invasions 20:461-473. https://doi.org/10.1007/s10530-017-1548-4

Richardson DM, Rejmánek M (2011) Trees and shrubs as invasive alien species-a global review. Divers Distrib 17:788-809. https://doi.org/10.1111/j.1472-4642.2011. 00782.x
Ruggera RA, Blendinger PG, Gomez MD, Marshak C (2016) Linking structure and functionality in mutualistic networks: do core frugivores disperse more seeds than peripheral species? Oikos 125:541-555. https://doi.org/10. 1111/oik.02204

R Development Core Team (2016) R: a language and environment for statistical computing. R Foundation for Statistical Computing.

Schaefer HM, Ruxton GD (2011) Plant-Animal Communication. Oxford University Press

Schaefer HM, Schmidt V, Winkler H (2003) Testing the defence trade-off hypothesis: how contents of nutrients and secondary compounds affect fruit removal. Oikos 102:318-328. https://doi.org/10.1034/j.1600-0706.2003. 11796.x

Schaefer HM, Schaefer V, Levey DJ (2004) How plant-animal interactions signal new insights in communication. Trends Ecol Evol 19:577-584. https://doi.org/10.1016/j.tree.2004. 08.003

Schaefer HM, Schaefer V, Vorobyev M (2007) Are fruit colors adapted to consumer vision and birds equally efficient in detecting colorful signals? Am Nat 169:S159-S169. https://doi.org/10.1086/510097

Singleton VL, Orthofer R, Lamuela-Raventos RM (1999) Analysis of total phenols and other oxidation substrates and antioxidants by means of folin-ciocalteu reagent. Methods Enzymol 299C:152-178

Sirombra MG, Mesa LM (2012) A method for assessing the ecological quality of riparian forests in subtropical Andean streams: QBRy index. Ecol Indic 20:324-331. https://doi. org/10.1016/j.ecolind.2012.02.021

Stournaras KE, Prum RO (2015) Fruit advertisement strategies in two Neotropical plant-seed disperser markets. Evol Ecol. doi: 10.1007/s10682-015-9766-7

Thuiller W, Gallien L, Boulangeat I et al (2010) Resolving Darwin's naturalization conundrum: a quest for evidence Wilfried. Divers Distrib 16:461-475. https://doi.org/10. 1111/j.1472-4642.2010.00645.x

Traveset A, Richardson DM (2011) Mutualisms: Key drivers of invasions ... key casualties of invasions. In: Richardson DM (ed) Fifty years of invasion ecology: the legacy of Charles Elton. Wiley-Blackwell, Oxford, pp 143-160

Traveset A, Richardson DM (2014) Mutualistic interactions and biological invasions. Annu Rev Ecol Evol Syst 45:89-113. https://doi.org/10.1146/annurev-ecolsys-120213-091857

Valido A, Schaefer HM, Jordano P (2011) Colour, design and reward: phenotypic integration of fleshy fruit displays. J Evol Biol 24:751-760. https://doi.org/10.1111/j.14209101.2010.02206.x

Publisher's Note Springer Nature remains neutral with regard to jurisdictional claims in published maps and institutional affiliations. 